NASA Technical Memorandum 103227

AIAA-90-2582

\title{
Performance Characterization of a Segmented Anode Arcjet Thruster
}

Francis M. Curran

National Aeronautics and Space Administration

Lewis Research Center

Cleveland, Ohio

David H. Manzella

Sverdrup Technology, Inc.

Lewis Research Center Group

Brook Park, Ohio

and

Eric J. Pencil

National Aeronautics and Space Administration Lewis Research Center

Cleveland, Ohio

Prepared for the

21st International Electric Propulsion Conference cosponsored by the AIAA, DGLR, and JSASS Orlando, Florida, July 18-20, 1990

\section{N/SA}




\title{
PERFORMANCE CHARACTERIZATION OF A SEGMENTED ANODE ARCJET THRUSTER
}

\author{
Francis M. Curran \\ NASA Lewis Research Center \\ Cleveland, Ohio 44135 \\ David H. Manzella \\ Sverdrup Technology, Inc. \\ Lewis Research Center Group \\ Brook Park, Ohio 44142 \\ Eric J. Pencil \\ NASA Lewis Research Center \\ Cleveland, Ohio 44135
}

\begin{abstract}
A modular, $1-2 \mathrm{~kW}$ class arcjet thruster incorporating a segmented anodelnozzle was operated on a thrust stand to obtain performance charcteristics of the device and to further study its operating characteristics under a number of experimental conditions. The nozzle was composed of five axial conducting segments isolated from one another by boron nitride spacers. The electrical configuration allowed the current delivered to the arcjet to be collected at any combination of segments. Both the current collected by each segment, and the potential difference between the cathode and each segment were monitored throughout the test period.

As in previous tests of a similar device, current appeared to attach diffusely in the anode when all of the segments were allowed to conduct. Improvements to the device allowed long term (4 - 8 hour) operation at steady-state and operating characteristics were repeatable over extended periods. Performance characteristics indicated that the segmented anode reasonably simulates the behavior of solid anodes of similar geometry. Current distribution depended on flow rate as the arc attachment moved downstream in the nozzle with increases in the mass flow rate. The current level had little effect on current distribution on the anode segments. Thrust measurements indicated that the current distribution in the nozzle did not significantly affect performance of the device.
\end{abstract}

\section{INTRODUCTION}

The past seven years have seen an extensive research effort directed toward the development of low power (1 - $2 \mathrm{~kW}$ class) arcjet technology for use in north-south stationkeeping of geosynchronous communications satellites. While maintaining compatibility with current and next generation spacecraft subsystems, these thrusters will provide significant performance improvements over existing, state-of-art, resistojet and chemical systems. The propellant savings realized can be used to reduce launch mass, and/or increase payload, and/or to increase satellite lifetime.

To date, on-going research and development programs have met many of the technology goals necessary for successful application of arcjet systems. These include development of a pulse width modulated power processing unit with an integrated, pulsed, high voltage starting circuit; ${ }^{1}$ demonstration of stable, reliable operation on hydrazine decomposition products at specific impulse levels between 450 and 500 seconds; ${ }^{2-5}$ successful completion of an automated, cyclic lifetest $;{ }^{6}$ and the recent assembly and testing of a flight-type arcjet system. 7,8 In addition to this type of component and system level testing, attempts to assess the impacts of arcjet systems on spacecraft subsystems are also in progress. Langmuir probe surveys of the plume have provided electron number densities and temperatures, ${ }^{9-11}$ and these have been used to model the effects of the plume on communications signals. 12,13 Also, a NASA sponsored program aimed at documenting arcjet/spacecraft interactions is to be completed this year. ${ }^{14}$ 
Arcjet technology development programs have been successful in bringing the arcjet nearly to flight readiness and an arcjet propulsion system has recently been baselined on a commercial communications satellite. There remain, however, questions about the physical processes of the device. For example, although the arcjet performance is significantly above that available with existing technology, arcjet efficiency is in the 30 to 40 percent range. Efforts to increase this have met with little success. The fundamental energy input and loss mechanisms are not well understood, and significant performance gains, if they are possible, will likely require a better understanding of the fundamental operating phenomena. Cathode emission processes have been studied, 15 as have the effects of nozzle contour. ${ }^{16}$ A recent study of current attachment in the nozzle provided insights into energy input regions, ${ }^{17}$ and extensive efforts have been directed toward the development of a numerical model of the arcjet. ${ }^{18}$

This report details the results from a continuing experimental program aimed at providing insight into arc energy deposition in the nozzle, the nature of the arc attachment, and its effects on performance characteristics of the device. A companion paper details a preliminary spectroscopic analysis of the arcjet plume and the effects of electrode configuration. ${ }^{19}$ A modular arcjet incorporating a segmented anode/nozzle was assembled and tested. This arcjet was similar to one reported in a previous study, ${ }^{17}$ but included design improvements that allowed extended operation. The segmented nozzle had the same critical dimensions as baseline nozzles used in many previous tests in this laboratory, $15,16,20$ but the isolated segments allowed the examination of the effects of the current distribution on both operating characteristics and performance level.

\section{APPARATUS}

Arcjet Thruster. Figure 1 shows a cutaway schematic of the arcjet thruster used in the tests described in this report. Aside from the segmented anode, this thruster is identical to those used in many tests in this laboratory. $15,16,20$ A $3.2 \mathrm{~mm}$ diameter, 2 percent thoriated tungsten rod about $190 \mathrm{~mm}$ in length was used as the cathode. The tip half angle was ground to 30 degrees to match the converging side of the anode. The modified compression-type fitting was used to feed the cathode through the rear insulator and to lock it in place once the gap was set. This fitting was held in place by a center-drilled holding bolt.

Propellant entered the arcjet from the side of the rear insulator. The propellant tube was threaded into a cylindrical anchor located inside the rear insulator. The axial center bore of this anchor allowed passage of both the cathode and an insulating alumina sheath. This design isolated the propellant system from the electrodes

The rear insulator, front insulator, and compression plunger shown in Figure 1 were all made from high purity boron nitride. An inconel spring was placed between the propellant tube anchor and plunger to ensure compression at the forward seals (ie. front insulator to injector disk and injector disk to nozzle). Where necessary, stainless steel washers were inserted to adjust the tolerance. Longitudinal grooves were machined into both the compression plunger and front insulator to allow propellant passage.

A molybdenum propellant injector disk made with two $0.51 \mathrm{~mm}$ injection holes, drilled tangent to the inner surface, was used. The anode housing was stainless steel.

Graphite foil gaskets were inserted between critical sealing surfaces. The anode housing and the rear insulator were clamped together by two stainless steel flanges connected by four steel bolts. For this application, four additional holes were drilled in the front flange to accept insulating feedthroughs for the bolts needed to hold the anode clamping flange in place.

Segmented Anode. A cross-sectional schematic of the segmented anode is shown in Figure 2(a). The upstream segment was 2 percent thoriated tungsten and comprised both the converging side of the nozzle (30 degree half angle) and the constrictor $(\mathrm{Dc}=0.64 \mathrm{~mm}$; $\mathrm{Lc}=0.25 \mathrm{~mm})$. This first segment had been run previously, and some damage to the constrictor was noted before the initiation of the tests described in this report. This did not appear to seriously affect the operating characteristics of the arcjet. In earlier versions of this device, the next three anode segments were made from molybdenum. For these tests, tantalum was used in place of molybdenum because of its machining properties and higher melting point. A detailed drawing of one of these segments is shown in Figure 2(b). The thickness of each segment at the nozzle surface was $1.3 \mathrm{~mm}$ and a step was cut in each to align the stack. The tabs used for electrical 
connection were extended and small bolt holes were drilled in them so that electrical attachments could be made with stainless steel bolts. All boron nitride insulating disks were $0.25 \mathrm{~mm}$ thick at the nozzle surface and had steps machined to mate with those on the conducting segments. A detailed drawing of one of these disks is also shown in Figure 2 (b). The downstream end anode segment was 2 percent thoriated tungsten. A molybdenum flange was used to clamp the segments onto the body of the arcjet. This flange was $1.6 \mathrm{~mm}$ thick and four insulated rods, discussed previously, held it in place. Four inconel springs were inserted between the clamping flange and the tightening bolts to allow for thermal expansion and to hold the segments together tightly during high temperature operation.

When assembled, the segmented nozzle had a 20 degree half angle in the diverging section and an area ratio of 225 . A photograph of the assembled thruster is shown in Figure 3(a) and a view looking down the nozzle toward the throat is shown in Figure 3(b).

Assembly. Arcjet assembly was complicated by the fact that the force of the springs on the forward flange could push the nozzle insert toward the cathode. To avoid this, the interior spring was stiffened and the compression on the exterior springs was adjusted. Even with these precautions, there was some question about the actual cathode/anode spacing when the unit was pressurized. This will be discussed further in the results and discussion section. The anode segments comprising the diverging section of the nozzle were disassembled and reassembled occasionally over the course of the test period to allow insertion of new parts, the rest of the thruster remained assembled in an effort to ensure that the cathode/constrictor positioning would not change from test to test. The small size of the individual anode segments and spacers made exact positioning difficult. Every effort was made to center the segments. It is likely, however, that some variation in the anode stack occurred between tests due to the assembly and installation process. These will be discussed in more detail in the Results and Discussion section.

Electrical Configuration. The electrical arrangement used in the testing is shown in Figure 4 along with the anode segment numbering scheme. Each anode segment could be made conducting or non-conducting. In the course of testing it was found that three electrical configurations covered a wide range of current distribution on the anode. These three configurations are shown in Table 1 and were used almost exclusively in the test matrix.

A pulse width modulated power processing unit (PPU) was used to start and run the arcjet. Manual switches were used to connect and disconnect the anode segments from the PPU. Separate digital voltmeters and Hall current probes were used to monitor the potential difference between the cathode and each anode segment and the current passing through the segments, respectively. Outputs from each of the current probes were taken to an eight channel strip recorder.

Vacuum Facility. All tests described in this report were performed in a $0.91 \mathrm{~m}$ diameter cylindrical test section piece attached to a 0.91 $\mathrm{m}$ gate valve. The gate valve was mounted on a vacuum tank that was $1.5 \mathrm{~m}$ in diameter and $5 \mathrm{~m}$ long. Pumping was provided by four $30,000 \mathrm{lps}$ diffusion pumps backed by a rotary blower and two mechanical roughing pumps. During normal arcjet operation, ambient tank pressures on the order of $0.65 \mathrm{~Pa}$ were maintained.

For performance measurements, the arcjet was mounted on a flexure-type thrust stand situated in the spool piece. This thrust measurement device has been described in detail elsewhere. ${ }^{21}$ Small drifts $(<0.0002 \mathrm{~N})$ in the thrust zero were observed during testing. The maximum magnitude was less than one percent of the total thrust measurement and could have been due either to thermal effects caused by the increased temperature of the thruster or by the extra current carrying wires needed to connect all of the segments.

Thermal conductivity type mass flow controllers were used to regulate both the nitrogen and hydrogen mass flow rates.

Calibrations and Procedure. Prior to the start of testing, the current probes were calibrated using a commercially available, laboratory model dc power supply. The thrust stand was also calibrated before and after the test sequence using weights of known mass attached to the thruster cradle on the thrust stand. These could be raised and lowered using an external actuator.

In all tests a 2:1 hydrogen-nitrogen propellant mixture was used to simulate fully decomposed hydrazine. The propellant system incorporated a calibration tank for in-situ 
flowmeter calibrations. Both $3.73 \mathrm{E}-5 \mathrm{~kg} / \mathrm{s}$ and $4.97 \mathrm{E}-5 \mathrm{~kg} / \mathrm{s}$ mass flow rates were used in the tests.

\section{RESULTS AND DISCUSSION}

General Comments. As noted in the section on arcjet assembly, the small size and close tolerances of the nozzle segments made exact alignment through the assembly and installation process difficult. Also, the high heat loads on the segments caused some damage to the segments similar to that described in a previous paper. ${ }^{17}$ This damage mainly took the form of localized melting, particularly on segment 2 . Because of these test-to-test variations in the physical condition of the nozzle and the anode connections, small differences in the operating characteristics of the device were observed. For example, on some startups, the current distribution observed in configuration 1 shortly after a start was near the steady state distribution, with approximately half of the current collected on the segment furthest downstream. During other tests with the same electrical configuration much of the current ( $>5 \mathrm{~A}$ ) was initially collected on segment 2 , and the redistribution to the steady state condition took tens of minutes. Despite these complications, stable arcjet operation was observed throughout most of the test periods and the trends and conclusions discussed in this report were not significantly impacted by test-to-test variations in operating conditions.

In earlier tests of a similar device, 17 no allowance was made for differential thermal expansion and this limited the maximum duration of test runs to approximately four minutes. After this period, operation became erratic. The design changes detailed in the Apparatus section effectively addressed issues related to thermal expansion and steady state operation was demonstrated over multi-hour periods.

Startup and Transition. In most test sequences, the arcjet was started in configuration 1 with the power supply current preset to $10 \mathrm{~A}$ and a mass flow rate of $4.97 \times 10^{-5} \mathrm{~kg} / \mathrm{s}$. As in previous testing, a brief current surge was seen on the first segment upon startup. This starting transient for the arcjet has been examined previously 17 and will not be discussed in any detail in this report. Most of the current moved downstream to attach in the diverging section of the nozzle very rapidly. Following startup, fluctuations were observed on the current traces before steady operation was obtained. Visible fluctuations in the plume were also observed during this period, often accompanied by some sparks. Similar starting transients have been observed in many previous arcjet tests. $6,16,20,21$ One possible explanation for this behavior is motion of the arc attachment points on the electrodes before the steady state condition was reached. Examination of segment 2 after testing always showed damage in the form of some localized melting which probably occured at startup. These irregularities in the surface may have caused localized current attachment that persisted for some time and led to motion of the attachment zone on both the anode and the cathode. It was also found that by switching all of the current to the segment farthest downstream, into configuration 2, immediately following startup, the fluctuations disappeared and stable operation was attained very rapidly.

In some tests the temperature of segment 5 was measured with a two color pyrometer. It was found that the nozzle reached thermal equilibrium very rapidly. Over 95 percent of the steady state value was reached within two minutes of startup. The steady state value of approximately $1450 \mathrm{~K}$ was $200-300 \mathrm{~K}$ above normal operating temperatures for similar devices with non-segmented anodes. This was attributed to reductions in conductive cooling due to the insulating spacers.

Operating Characteristics and Performance. As previously noted, stable arcjet operation was observed in each of the electrical configurations shown in Table 1. In typical test sequences, the arcjet was started in configuration 1 and run until steady state operation was attained. Once the steady state condition was reached, the arcjet was switched to another configuration, data were taken and the arcjet was returned to configuration 1. This sequence was repeated for each operating point and the current/voltage characteristics were found to be very repeatable over each test period indicating that the thruster maintained its structural integrity throughout the tests. The same philosophy was also used in changing operating points, i. e. the initial test point (mass flow rate, current, and electrical configuration) was retaken at the end of each test period in order to determine whether any major changes in operating characteristics had occured during the test period.

Typical voltage-current characteristics of the thruster running in configuration 1 at the highest mass flow rate are shown in Figure 5. Also 
included in the figure is a data set taken from previous arcjet tests in which standard nozzle inserts of similar dimensions were used. From the figure it can be seen that the curves are offset by 25 to 30 volts across the current range. This voltage offset is not fully understood at present. It is possible that this offset was due to differences in the anode to cathode spacing, or arc gap, between the tests with the solid and segmented anodes. As noted in the assembly section, the gapping procedure was complicated by the springs inserted to allow for differential thermal expansion in the nozzle. The magnitude of the impedence change, approximately $3 \mathrm{ohms}$ at $10 \mathrm{~A}$, makes it unlikely that the difference is due to added resistance in the extra cabling and connectors required to operate the segmented anode. Thrust measurements taken during testing indicated that the noted differences in the currentvoltage characteristics did not significantly impact the performance characteristics of the device.

Table 2 presents data from a typical test run in which the arcjet was operated at constant current and mass flow rate in each of the three configurations. It should be noted that due to the combined uncertainties in the current measurements for all of the segments, the total currents for each configuration do not add to exactly $10 \mathrm{~A}$ in each case. During the experiment, current was set to $10 \mathrm{~A}$ and this setting was not changed as the configurations were changed. Thus, $10 \mathrm{~A}$ was used to calculate the power in each case. The data show that the arcjet ran at the lowest operating voltage when all the segments were connected (configuration 1). When all of the current was switched to the last segment (configuration 2), the overall operating voltage increased by about 5 volts. This same increase in voltage was observed when only the last segment was made non-conducting (configuration 3 ). As noted in a previous report, 17 the increase in operating voltage observed when the arcjet was switched from configuration 1 to configuration 3 suggests that the anode fall voltage increases when the arc attaches upstream in the nozzle. The difference in potential between segment 4 and segment 5 when segment 5 was isolated was about the same as observed previously. This supports the conclusion that the anode fall in this region is on the order of $10-20$ volts.

The floating potentials of the segments when only segment 5 was conducting provide a rough estimate of the regions of energy input in the device. This is plotted for a typical case in
Figure 6. Only about 40 percent of the total voltage drop occurred in the constrictor segment. This indicates that a significant amount of the total energy dissipated in the device was input in the diverging section of the nozzle. The effects this had on thrust will be discussed in a following section.

To examine the effect of mass flow rate on the current distribution the arcjet was run at two different mass flow rates, $4.97 \times 10^{-5} \mathrm{~kg} / \mathrm{s}$ and $3.73 \times 10^{-5} \mathrm{~kg} / \mathrm{s}$, in configuration 1 at $10 \mathrm{~A}$. The flow rate range approximates the worst case expected in a blowdown system on a communications satellite. The current to each segment and the current distribution on each segment are shown in Figures 7 (a) and (b), respectively. To calculate current densities, it was assumed that the current to each segment was distributed evenly across the interior surface of the segment except in the case of segment 1 . For this, only the constrictor area was assumed to be conducting, (ie. it was assumed that current was not collected in the converging section of the nozzle, on the anode housing which was in direct electrical contact with segment 1 , or on the downstream face of the segment). Calculated values of the current density on the constrictor segment were high compared to those on the other segments and it is likely that this assumption was incorrect. This implies either that there was some current collected upstream in the converging section of the anode or that the actual collecting area in the constrictor was significantly larger than calculated due to damage caused during startup and/or steady state operation. Because of the uncertainties in the current collecting area and the fact that only small amounts of current were collected on this segment, the current densities on this segment will not be discussed further. From Figures 7(a) and (b) it can be seen that almost half of the total current was collected on segment 5 and that the current density profile, excluding segment 1 , peaked at segment 2 at the higher mass flow rate. This current distribution changed significantly as the mass flow rate was lowered by about 25 percent to the second flow rate tested. For this operating point, the current to the last segment was decreased by half, and the largest current increase was seen on segment 3 . The trends observed in this test indicate that the mass flow rate influences the current distribution in the nozzle and that the current distribution can be expected to change with time in a blowdown system. 
Finally, the total current to the device was found to have little effect on the current distribution in the nozzle. To study this, the arcjet was run in configuration 1 with a constant mass flow rate and the current was varied from 6 to $10 \mathrm{~A}$ in $2 \mathrm{~A}$ increments. The fractions of the total current that appeared on each segment for the three current levels used are shown in Table 3. From the table it can be seen that there was little difference between the 10 and $8 \mathrm{~A}$ operating points. While there were some differences between these and the $6 \mathrm{~A}$ case, no clear trend was evident. As there has been recent emphasis on low power arcjet operation, ${ }^{20}$ further study at lower currents may be warranted. The upper voltage limit of the power supply used in this study prohibited operation at lower current levels.

It was also of interest to obtain thrust measurements with the thruster operating in different electrical configurations in order to determine whether or not the current attachment location significantly impacted the performance of the device. In the course of earlier experiments on segmented anodes, ${ }^{17}$ significant changes in plume characteristics were observed as the electrical configuration was changed. For example, when the arcjet was switched to configuration 3 from configuration 1 , the emission from the $\mathrm{H}_{\beta}$ line $(486.1 \mathrm{~nm})$ became more prominent. When the arcjet was switched to configuration 2 the entire plume became more luminous. A detailed spectroscopic analysis of these changes is presented in a companion report. 19 Briefly, the differences in visible plume characteristics indicate that changes in the electrical configuration result in changes in the excited state populations of numerous plume species. Thus, it was concievable that the electrical configuration might have some impact on physical processes important to the efficiency of the device.

Typical performance data for the three different configurations were presented in Table 2. As noted earlier, the power input to the device was significantly above that observed in previous tests of thrusters with solid anodes. Figure 8 shows performance data taken with the segmented anode plotted along with data from previous tests of similar arcjets with solid nozzles. $6,16,20$ Specific impulse and efficiency are plotted vesus specific power in Figures 8 (a) and 8 (b), respectively. From the plots it can be seen that differences between nozzles are not significant. Thus, the use of the segmented anode to simulate a standard solid anode seems valid.
The data shown in Table 2 also demonstrate that the electrical configuration does not significantly affect the overall performance of the arcjet thruster. As the arcjet was switched from configuration to configuration slight differences in the thrust were observed, but these were not statistically significant. As previously noted, the visible changes in the plume characteristics caused by switching the electrical configuration indicated that the excited state populations of some plume species are configuration dependent. A companion report ${ }^{19}$ advances the argument that the observed variation in intensity with configuration was the result of changes in the electron energy distribution. From the performance data it is clear that these changes did not significantly affect the thrust characteristics of the device. Thus, based on this investigation of a convential nozzle geometry, it appears that arcjet performance cannot be significantly improved by changing the region of current attachment.

\section{CONCLUDING REMARKS}

A segmented anode/nozzle was tested in a 1 $2 \mathrm{~kW}$ class arcjet thruster in order to study the effects of current distribution on the operating characteristics and performance of the device. The effect of current level and mass flow rate on the anode current distribution was also examined. The electrical configuration was designed to allow current to be collected across any combination of segments. Both the current through each segment and the potential difference between each segment and the cathode were monitored. Performance measurements indicated that this modular arcjet with the segmented anode adequately simulated laboratory arcjets incorporating solid anode inserts of similar dimensions.

As in previous experiments, the current was found to attach diffusely in the diverging section of the anode when all of the segments were conducting. When all but the segment farthest downstream were isolated, the potentials observed between the cathode and the individual anode segments indicated that a significant amount of the power input to the arcjet ( $>50 \%$ ) was added in the diverging section of the nozzle. The current distribution in the nozzle was found to be dependent on the mass flow rate.

Finally, thrust measurements indicated that the electrical configuration does not significantly affect the performance of the device. This implies that the changes in the electric field in 
the nozzle that occur as a result of the changes in the current distribution do not significantly impact the momentum transfer or loss mechanisms in the type of nozzle studied.

\section{REFERENCES}

1. Gruber, R. P.: "Power Electronics for a 1kW Arcjet Thruster, AIAA Paper 86-1507, June 1986, (NASA TM-87340).

2. Hardy, T. L.; and Curran, F. M.: "Low Power dc Arcjet Operation with Hydrogen/Nitrogen/Ammonia Mixtures," AIAA Paper 87-1948, June 1987. (NASA TM-89876).

3. Knowles, S. C., et al.: "Performance Characterization of a Low Power Hydrazine Arcjet. AIAA Paper 87-1057, May 1987.

4. Knowles, S. K.; and Smith, W. W.: "Arcjet Thruster Research and Technology, Rocket Research Co., Phase I, Final Report, 87-R1175, Aug. 1987.

5. Knowles, S. K.: "Arcjet Research and Technology, Phase II, Final Report," NASA Cr-182276, Rocket Research Co., Redmond, WA (to be published).

6. Curran, F. M.; and Haag, T. W.: "An Extended Life and Performance Test of a Low Power Arcjet," AIAA Paper 88-3106, July 1988 (NASA TM-100942).

7. Yano, S. E.; and Knowles, S. K.: "Simulated Flight Qualification Test of an Engineering Model Arcjet System," presented at the 1989 JANNAF Meeting, Cleveland, OH, May 1989.

8. Knowles, S. K.; Yano, S. E.; and Aadland, R. S.: "Qualification and Lifetesting of a Flight Design Hydrazine Arcjet System" to be presented at the 1990 21st International Electric Propulsion Conference, Orlando, FL, July 1990.

9. Zana, L. M.: "Langmuir Probe Surveys of an Arcjet Exhaust," AIAA Paper 87-1950, July 1987. (NASA TM-89924).

10. Carney, L. M.: "An Experimental Investigation of an Arcjet Thruster Exhaust Using Langmuir Probes," Master's Thesis, University of Toledo, NASA TM-100258, December, 1988.

11. Carney, L. M.; and Sankovic, J. M.: "The Effects of Arcjet Operating Condition and Constrictor Geometry in the Plasma Plume," AIAA Paper 89-2723, July 1989. (NASA TM-102284).

12. Carney, L. M.: "Evaluation of the Communications Impact of a Low Power Arcjet Thruster," AIAA Paper 88-3105. July 1988.
13. Ling, H.; et al.: "Reflector Performance Degradation Due to an Arcjet Plume," presented at the 1989 Antenna Applications Symposium, Monticello, IL, September 1989.

14. Zafran, S.: "Arcjet System Integration Development Program," Final Report, NASA CR- 185266, TRW, Inc., Redondo Beach, CA, (to be published).

15. Curran, F. M.; Haag, T. W.; and Raquet, J. F.: "Arcjet Cathode Phenomena," presented at the 1989 JANNAF Meeting, Cleveland, $\mathrm{OH}$, May 1989.

16. Curran, F. M.; Sovie, A. L.; and Haag, T. W.: "Arcjet Nozzle Design Impacts," presented at the 1989 JANNAF Meeting, Cleveland, OH, May 1989.

17. Curran, F. M.; and Manzella, D. H.: "The Effect of Electrode Configuration on Arcjet Performance," AIAA Paper 89-2722, July 1989. (NASA TM-102346).

18. Butler, G. W.; King, D. Q.; and Kashiwa, B. A.: "Numerical Modeling of Arcjet Performance," AIAA Paper 90-1471, presented at the 21st Fluid Dynamics, Plasmadynamics, and Laser Conference, Seattle, WA, June 1990.

19. Manzella, D. H.; Curran, F. M.; Myers, R. M.; and Zube, D. M.: "Preliminary Investigations of an Arcjet Plume," to be presented at the 21st International Electric Propulsion Conference, Orlando, FL, July 1990.

20. Curran, F. M.; and Sarmiento, C. J.: "Low Power Arcjet Performance," to be presented at the 21st International Electric Propulsion Conference, Orlando, FL, July 1990.

21. Haag, T. W.; and Curran, F. M.: "Arcjet Starting Reliability: A Multistart Test on Hydrogen/Nitrogen Mixtures." AIAA Paper 87-1061, May 1987 (NASA TM-89867). 
Table 1. Electrical configurations. (Sce Figure 4)

Switch positions

Configuration

$\begin{array}{lllll}1 & 2 & 3 & 4\end{array}$

$\begin{array}{llllll}1 & 1 & 1 & 1 & 1 & 1 \\ 2 & 0 & 0 & 0 & 0 & 1 \\ 3 & 1 & 1 & 1 & 1 & 0\end{array}$

$(0=$ Switch open; $1=$ Switch closed $)$

Table 2. Typical operating characteristics with $\dot{\mathrm{m}}=4.97 \mathrm{E}-5 \mathrm{~kg} / \mathrm{s}$ and $\mathrm{I}=10 \mathrm{~A}$.

\section{$\underline{\text { Segment }}$}

\begin{tabular}{|c|c|c|c|c|c|c|c|c|c|c|c|c|c|c|}
\hline & \multicolumn{5}{|c|}{ Voltage, V } & \multicolumn{5}{|c|}{ Current, A } & Thrust & ISD & $\underline{\mathrm{P} / \mathrm{m}}$ & Efficiency \\
\hline Configuraion & $\underline{1}$ & $\underline{2}$ & 3 & $\underline{4}$ & 5 & 1 & $\underline{2}$ & 3 & $\underline{4}$ & 5 & $\overline{(N)}$ & (s) & $(\overline{\mathrm{kJ} / \mathrm{kg}})$ & \\
\hline 1 & 134.0 & 134.0 & 134.0 & 134.0 & 134.0 & $\begin{array}{c}0.2 \\
39.5\end{array}$ & $\begin{array}{c}1.1 \\
23.1\end{array}$ & $\begin{array}{c}1.4 \\
15.1\end{array}$ & $\begin{array}{c}26 \\
181\end{array}$ & $\begin{array}{l}4.9 \\
28\end{array}$ & 0.219 & 450 & 27,000 & 35.2 \\
\hline 2 & 56.1 & 93.6 & 116.8 & 124.5 & 138.9 & $\begin{array}{l}0.0 \\
0.0\end{array}$ & $\begin{array}{l}0.0 \\
0.0\end{array}$ & $\begin{array}{l}0.0 \\
0.0\end{array}$ & $\begin{array}{l}0.0 \\
0.0\end{array}$ & $\begin{array}{c}10.0 \\
5.8\end{array}$ & 0.220 & 452 & 27,900 & 34.3 \\
\hline 3 & 139.3 & 139.3 & 139.3 & 139.3 & 123.5 & $\begin{array}{c}0.4 \\
79.0\end{array}$ & $\begin{array}{c}27 \\
57.0\end{array}$ & $\begin{array}{c}60 \\
63.7\end{array}$ & $\begin{array}{l}12 \\
8.5\end{array}$ & $\begin{array}{l}0.0 \\
0.0\end{array}$ & 0.200 & 451 & 28,000 & 34.1 \\
\hline
\end{tabular}

(Note: Second row under current for each configuration is current density, $\mathrm{A} / \mathrm{cm}^{2}$ ). 
Table 3. Fractional current per segment at three current levels.

(Configuration 1; $\mathrm{m}=4.97 \mathrm{E}-5 \mathrm{~kg} / \mathrm{s}$ )

\section{Fractional Current}

$$
\mathrm{I}_{\text {total }}=\quad \underline{6 \mathrm{~A}} \quad \underline{8 \mathrm{~A}} \quad \underline{10 \mathrm{~A}}
$$

Segment \#

$\begin{array}{llll}1 & 0.0 & 0.01 & 0.02 \\ 2 & 0.16 & 0.12 & 0.11 \\ 3 & 0.21 & 0.15 & 0.14 \\ 4 & 0.17 & 0.22 & 0.26 \\ 5 & 0.45 & 0.49 & 0.49\end{array}$

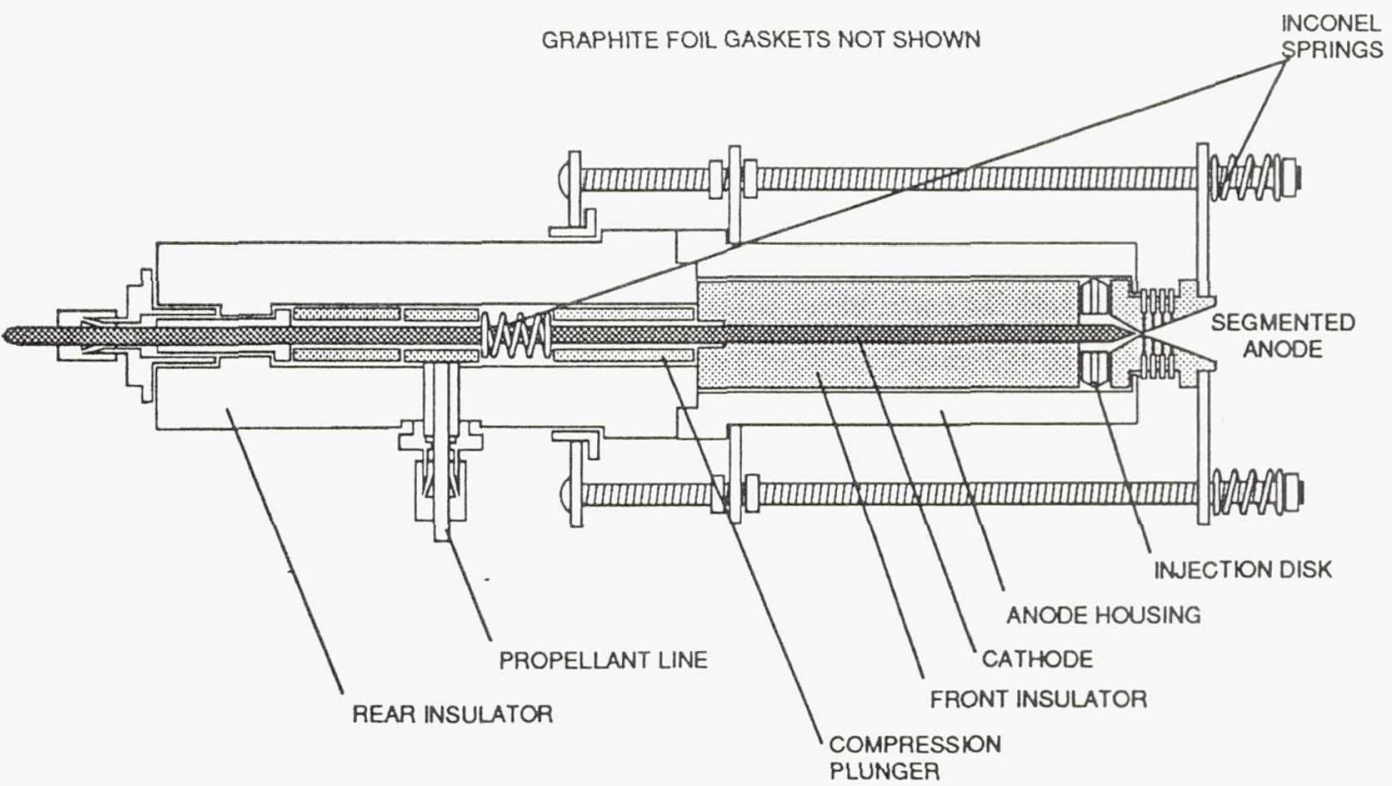

Figure 1. Cross-sectional schematic of the arcjet thruster. 


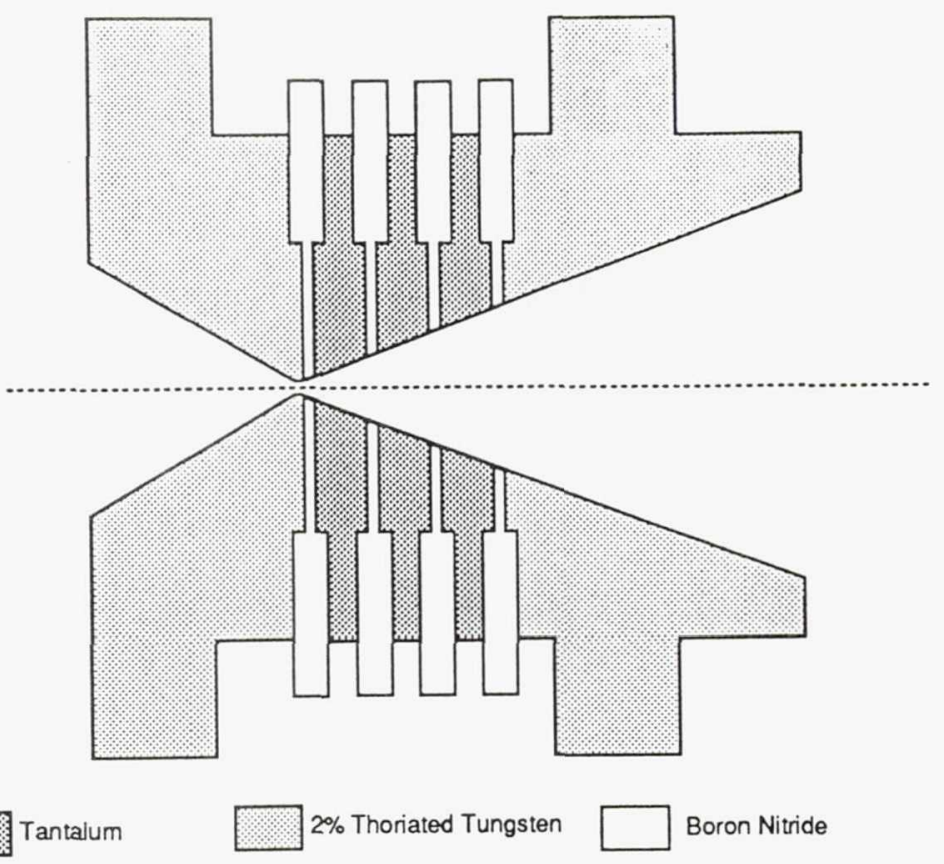

a) Cross-sectional schematic of the segmented anode.
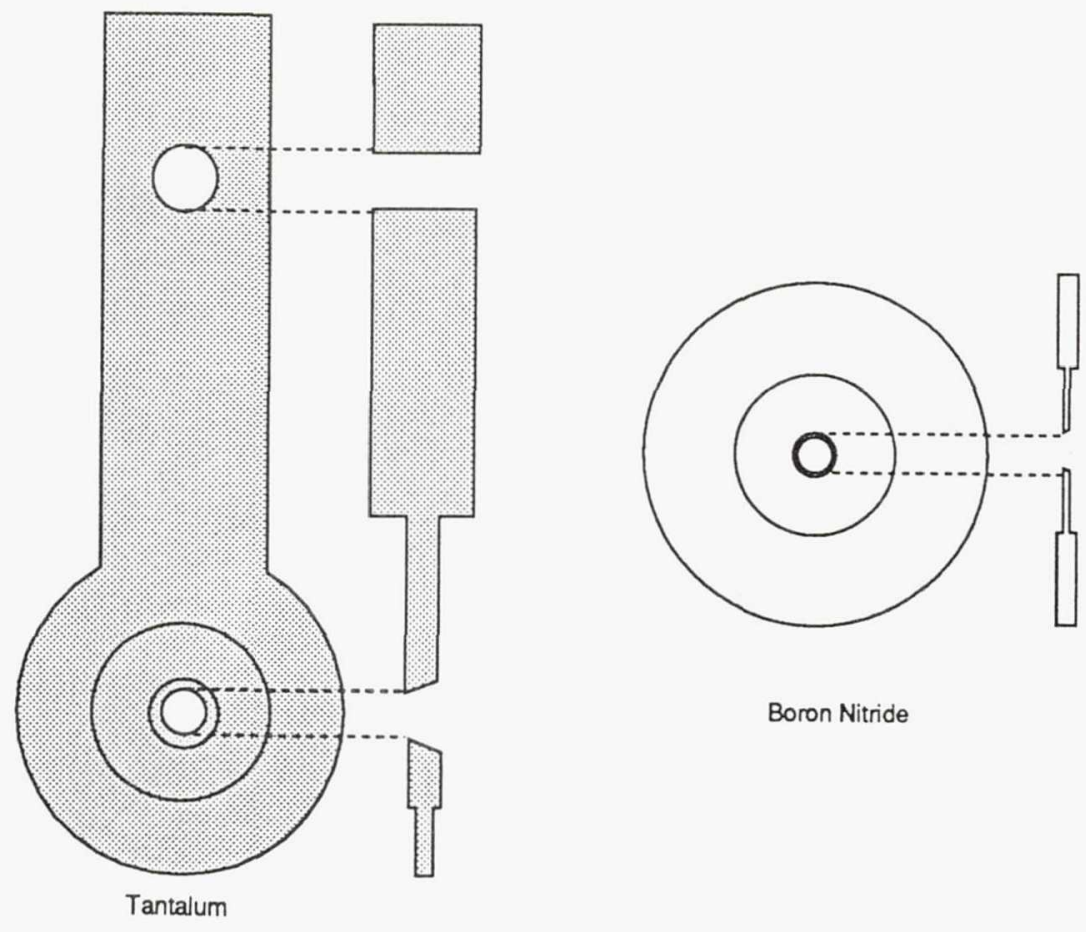

Boron Nitride

b) Molybdenum anode segment and boron nitride spacer.

Figure 2. Segmented anode/nozzle schmatics. 


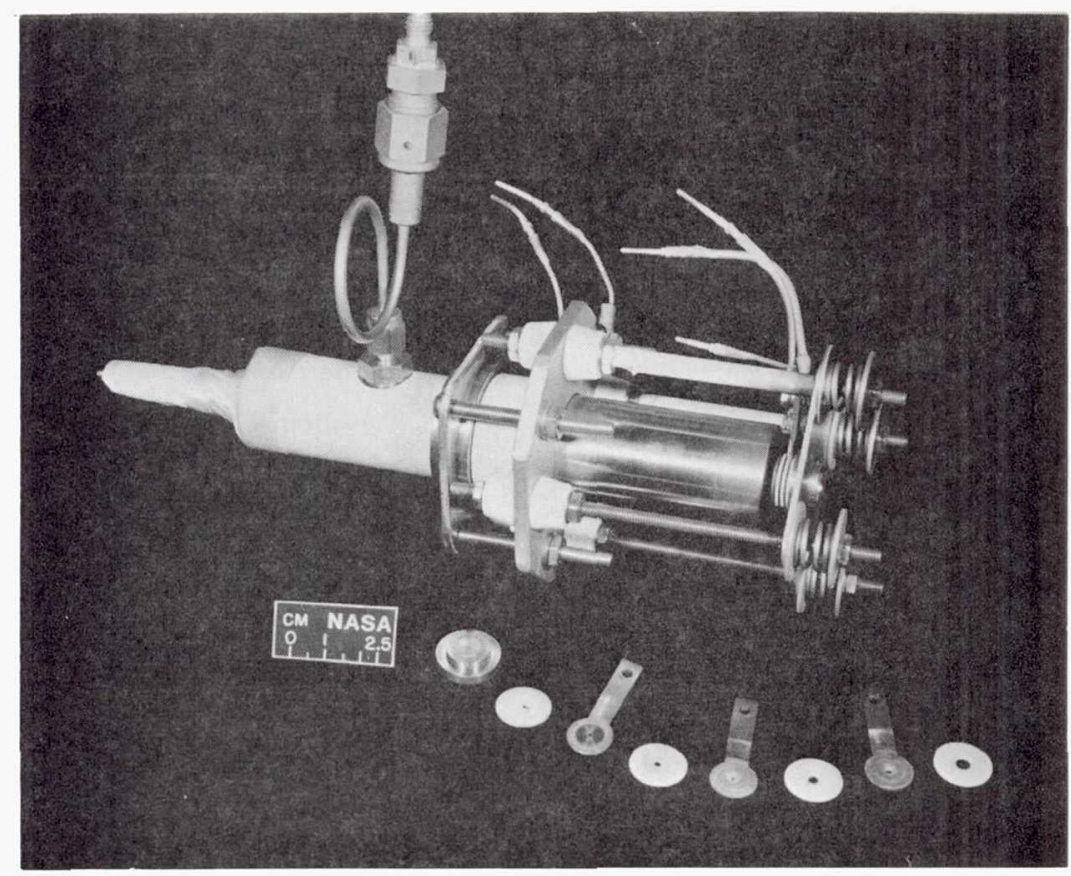

a) Photograph of assembled arcjet.
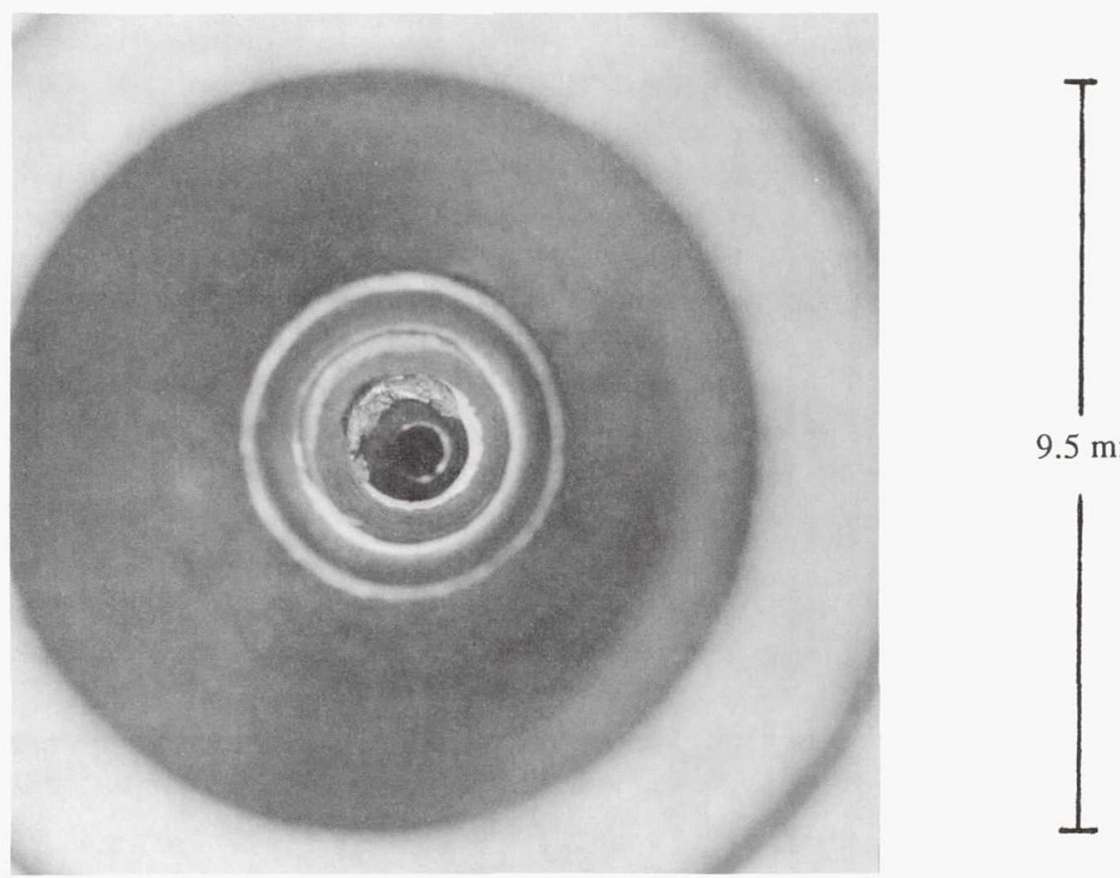

$9.5 \mathrm{~mm}$

b) View of assembled nozzle - looking upstream from the exit plane.

Figure 3. Photographs of arcjet and nozzle assembly. 


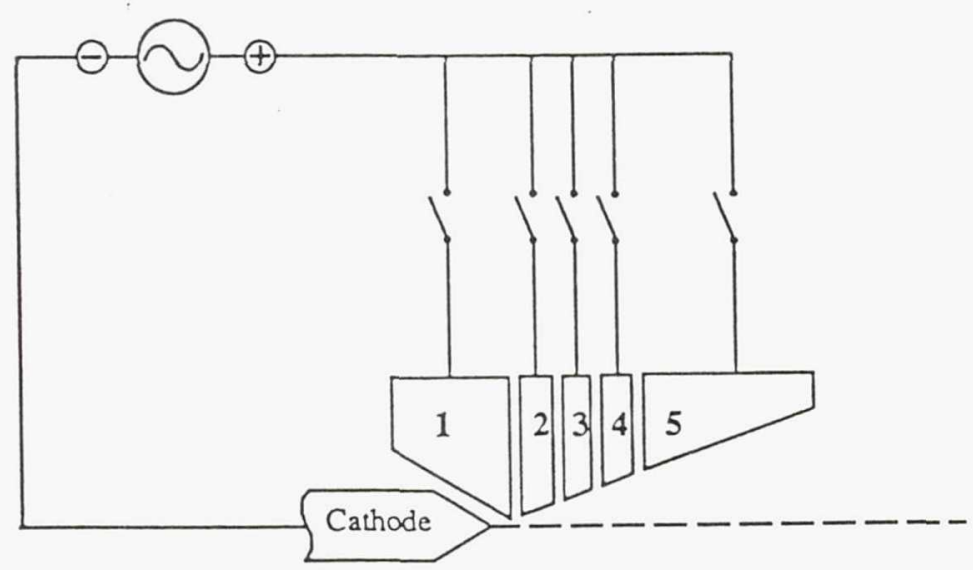

Figure 4. Simplified diagram of electrical configuration.

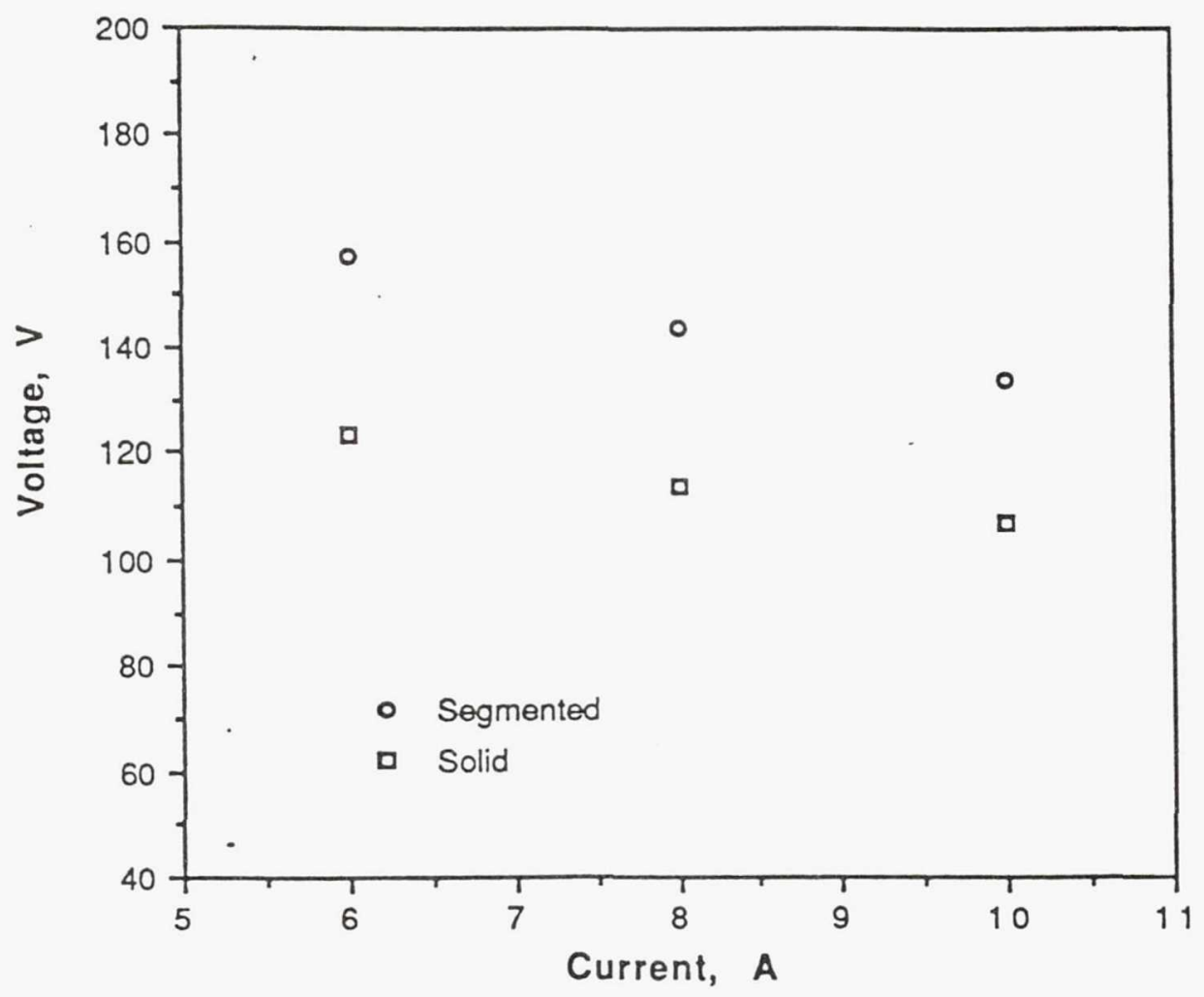

Figure 5. Arcjet voltage-current characteristics. 

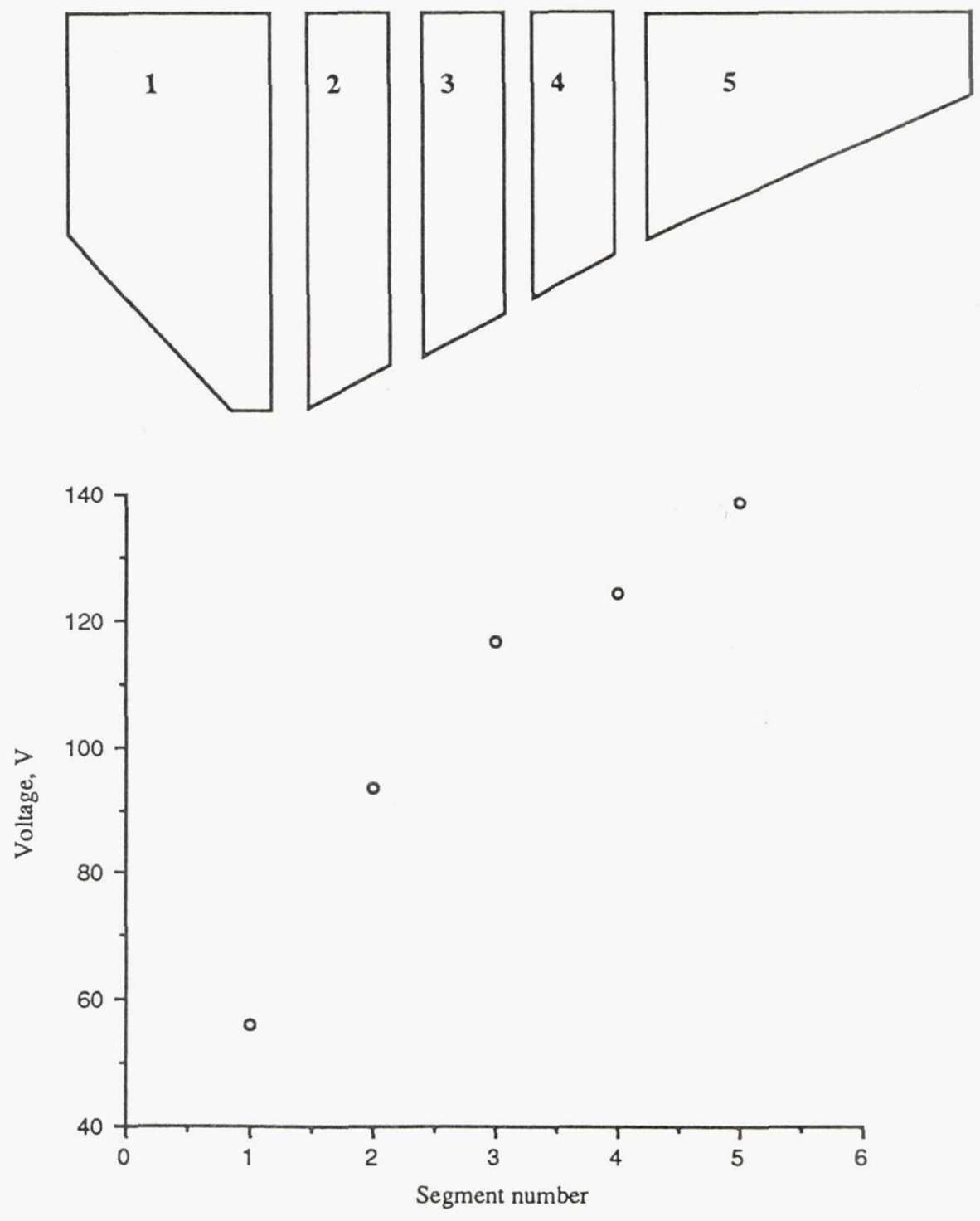

Figure 6. Arcjet voltage gradient - configuration 3. 

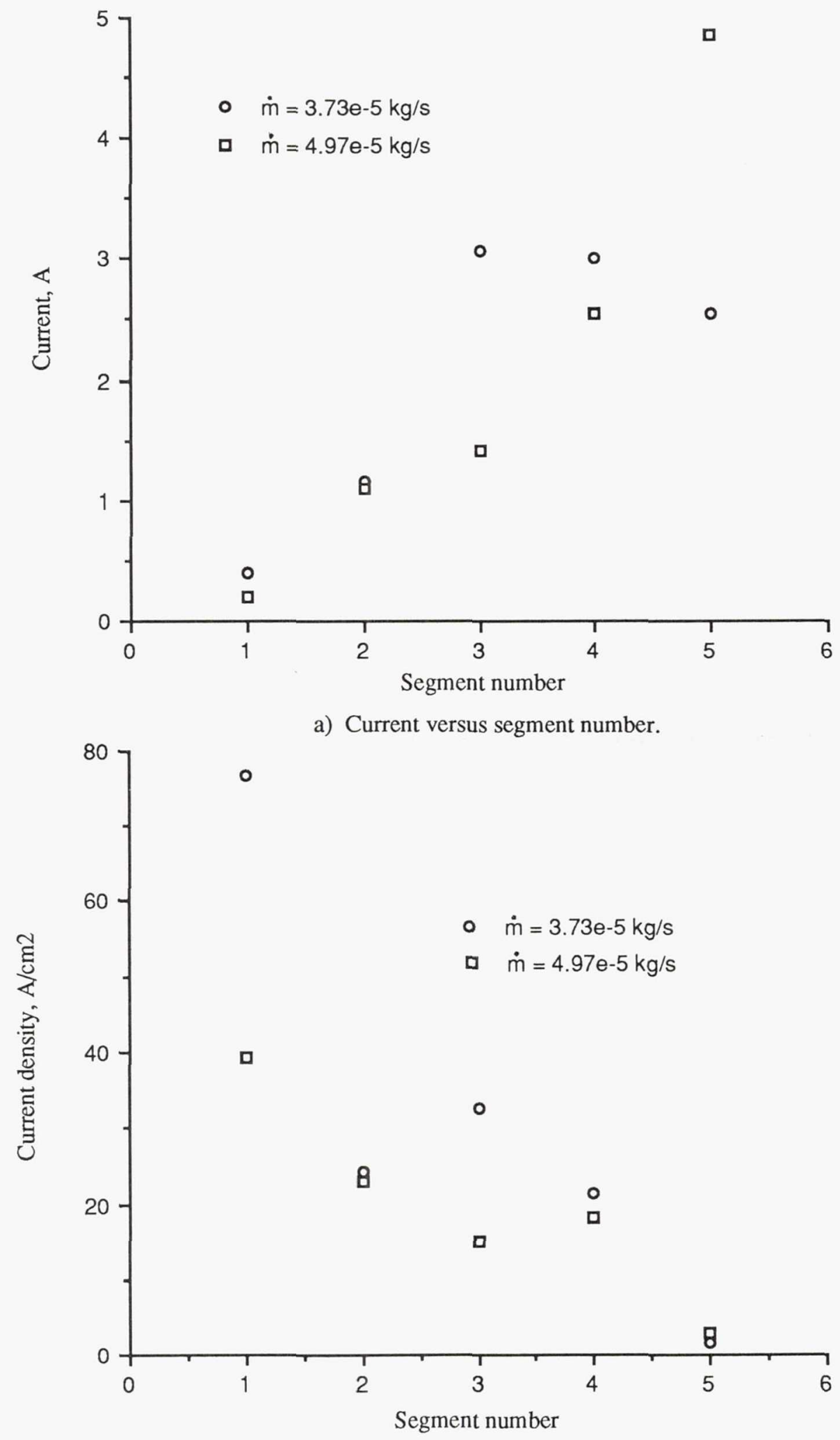

b) Current density versus segment number.

Figure 7. Current and current density to each segment - configuration 1. $(\mathrm{I}=10 \mathrm{~A})$ 


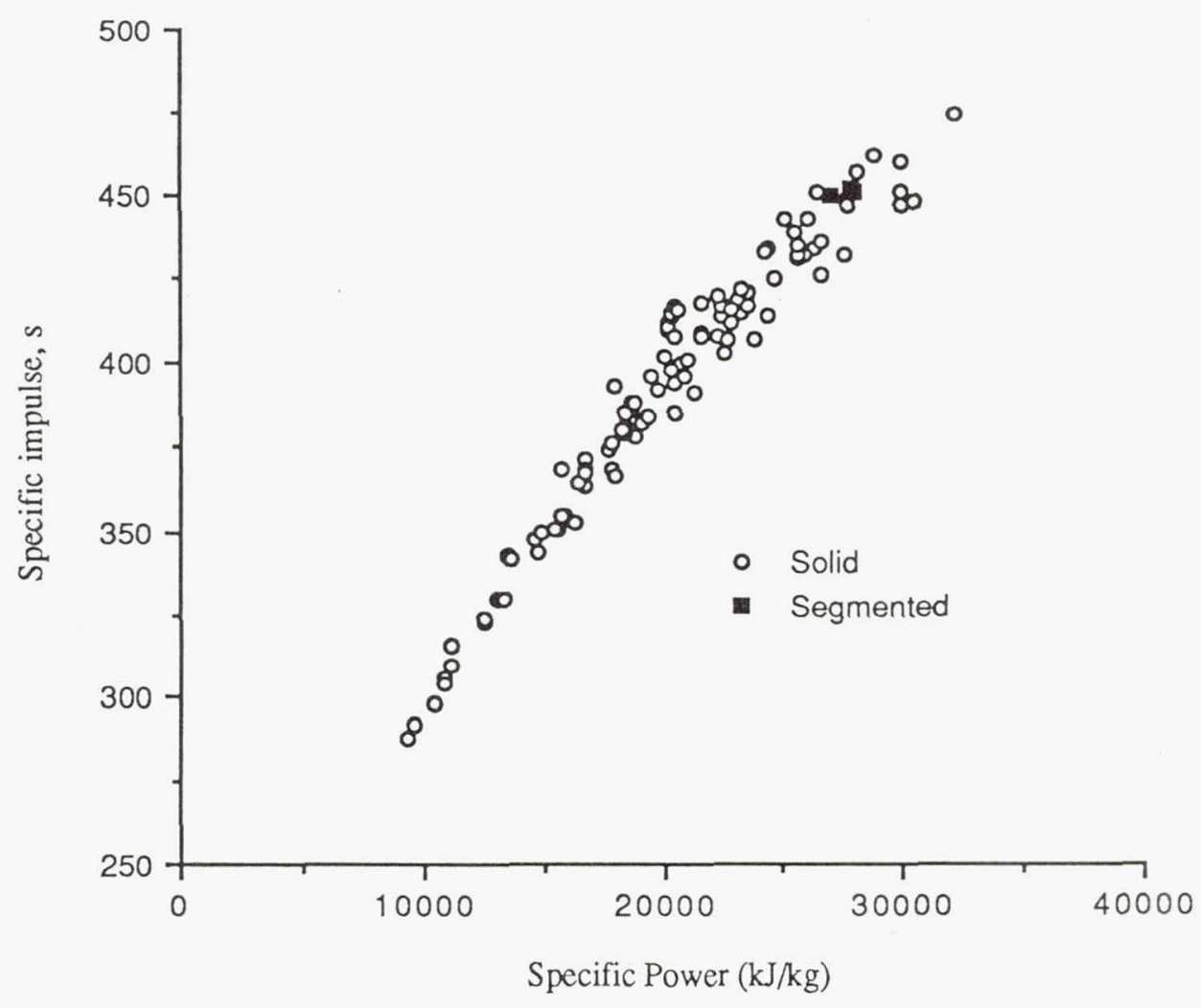

a) Specific impulse versus specific power.

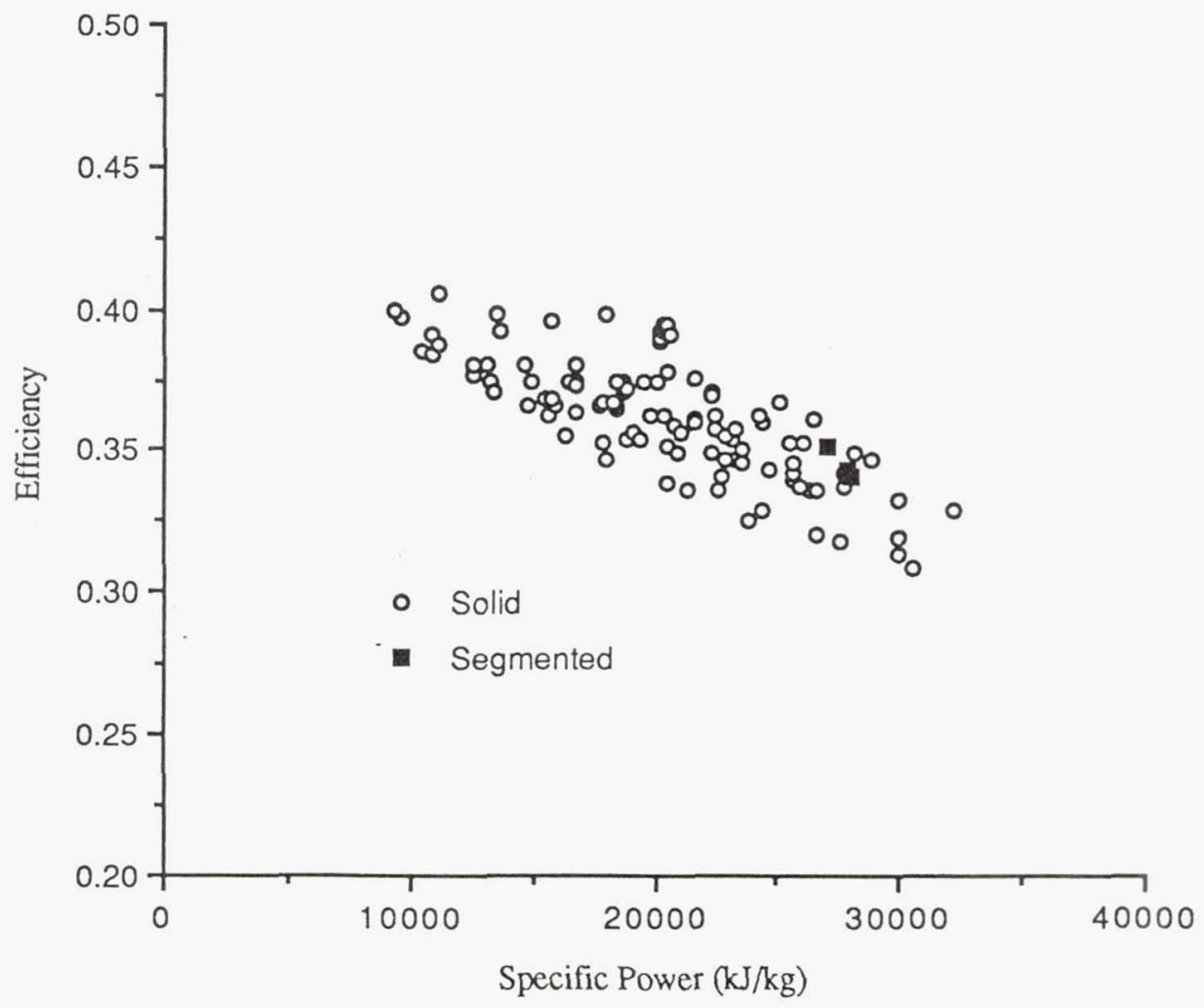

b) Efficiency versus specific power.

Figure 8. Solid versus segmented anode arcjet performance. 


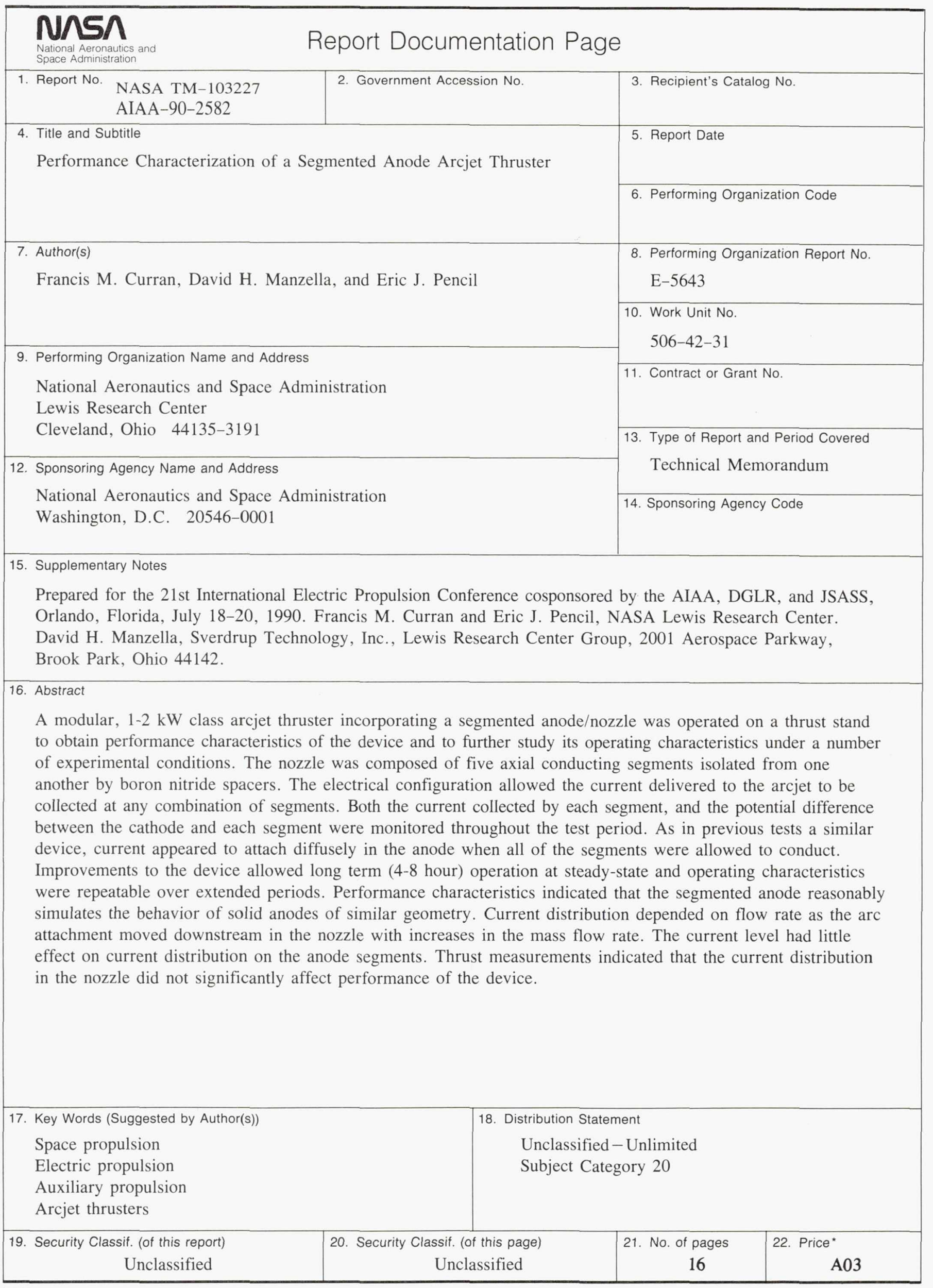

